\title{
The Effectiveness of a Chronic Obstructive Pulmonary Disease Computer Game as a Learning Tool for Nursing Students
}

\author{
Sing-Ling Tsai ${ }^{1}$, Sinkuo Chai ${ }^{2}$, Kai-Hsiang Chuang ${ }^{3}$ \\ ${ }^{1}$ Fu Jen Catholic University, Taiwan \\ ${ }^{2}$ Department of Health Services Management, China Medical University, Taichung, Taiwan \\ ${ }^{3}$ Lunghwa University of Science and Technology, Taiwan \\ Email: sltsai001@gmail.com, jesushepherd@gmail.com, skchai@mail.cmu.edu.tw
}

Received 29 April 2015; accepted 5 July 2015; published 9 July 2015

Copyright (C) 2015 by authors and Scientific Research Publishing Inc.

This work is licensed under the Creative Commons Attribution International License (CC BY). http://creativecommons.org/licenses/by/4.0/

(c) (i) Open Access

\begin{abstract}
Simulation games that are close to actual clinical situations can assist students in the learning process and, through the active presentation of subject material, help them acquire necessary knowledge. The aims of this study were to develop a computer game focused on caring for patients with chronic obstructive pulmonary disease (COPD) in the outpatient clinic and to evaluate the nursing students' change in knowledge and their satisfaction score after they played this computer game. This study had a randomized pre-/post-control experimental design. How to assess and care for patients with dyspnea episodes, the use of inhalants, the effects of weather changes, and breathing exercises for patients with COPD were the key content elements of the computer game developed by the study team. The COPD care knowledge test and satisfaction questionnaire were the evaluation instruments. Sixty-eight junior nursing students participated in this study. Of these 68 participants, 35 were randomly assigned to the control group and 33 were randomly assigned to the experimental group. Each group finished the pretest, then played the game for 20 minutes, and then did the post-test questionnaire. The results of this study determined that the COPD care knowledge score was significantly improved after playing the game in the experimental group $(t=$ $2.24, P<0.05)$. The experimental group responded that the computer game could help them clearly understand ways to take care of patients with COPD in the outpatient clinic. Important suggestions were to add reflection session after playing the computer game and to modify the fluency of the operation procedures. The experience and results of this study could apply not only to the teaching strategy for nursing students, but also for further developing a game for patient education.
\end{abstract}

\section{Keywords}

Computer Game, Student Nurse, Teaching Strategy, Outpatient Clinic, Pre-/Post-Control 


\section{Experimental Design}

\section{Introduction}

Game-based learning has been widely used in various fields. Although nursing teachers have designed gamebased teaching activities, few digital situational simulation games have been designed with a focus on nursing care for instructional purposes.

In the current era of advanced computer and information technology, the provision of simulation that is close to actual clinical situations can enable students to repeatedly practice techniques and provide instantaneous feedback on the teaching strategies, which can better guarantee patient safety and prevent patients from experiencing injuries and pain caused by poor nursing techniques. It has been verified that multimedia interactive teaching materials have a positive effect on the instruction of motor skills such as intravenous injection [1] [2], the teaching of examination techniques, and the accumulation of experiences in image interpretation [3].

Dye, Gillon and Sales [4] pointed out that students have suggested that a virtual learning environment can replace current teaching methods. Moreover, the establishment of future learning environments requires interdisciplinary cooperation. The successful development of virtual learning is subject to the support for professional techniques provided by a larger number of teachers. Thus, nursing faculties could organize a meaningful instructional content in cooperation with the digital design professions.

Johnston et al. [5] defined serious gaming as software applications where learners can immerse themselves in virtual environment activities that allow them to tackle problems relevant to their discipline and proposed that digital games could support the strategies for nursing education. Their team implemented digital games to teach research methods and statistics for students in nursing and social science.

Chia [6] designed a game to facilitate $2^{\text {nd }}$ year diploma nursing student to learn knowledge of nursing intervention for patients with COPD in a clinical setting and found positive responses from students. Yet, the author did not delineate whether the clinical settings was hospitalization or outpatient care.

The outpatient care of COPD was chosen as the theme of the digital game at a personal computer. The care strategies in outpatient were important for long-term care of patients with COPD and could be presented as a digital game to facilitate the learning process of nursing students communicating with COPD patients.

Tinker and While [7] analyzed 23 evidenced studies focused on COPD patient care. They found five essential care themes: quitting smoking, managing dyspnea, exercising, providing palliative care and communicating care by telephone. Jonsdottir [8] reviewed evidence-based nursing care studies and added home respiratory care, a self-care program, respiratory care by telephone and home care as essential components of care for patients with COPD. The health management including assessing health status of subjects, giving regular health lectures, smoking cessation counseling, encouraging regular exercise, rehabilitative training, psychological counseling, and regular follow-up was an effective community-based strategy for the prevention and management of COPD in China [9].

The study done on patients in Taiwan found that patients with COPD would take their physicians' advice to exercise. They usually practiced Chinese Kuo-Fu with abdominal breathing as a form of regular exercise [10].

For care of patients with COPD, assessment and care of dyspnea episodes (including the use of inhalants), coping with the effects of weather changes, and breathing exercises were important components of the outpatient clinic.

Among creative nursing teaching methods, playing a game is an interesting learning activity. Metcalf and Yankou [11] stressed that a game could strengthen critical thinking and create an interesting learning atmosphere.

Lever [12] designed a car racing game to teach research. The major concepts and terms in research were designed as 50 car-racing hurdles. Each student could choose a car of a different color. Car speed was decided by rolling the dice. Four to six students as a group played the car-racing game on a paper poster. The important research terms were described and explained before the car-racing game. The game's winner would receive a crown. The students who played this game felt the learning was active and interesting.

Associated with the interesting game process, de Bono [13] presented a choice of six "thinking hats", each hat representing a different perspective. The player in the white hat took the objective position. The player in the red 
hat took the emotional and intuitive position. The player in the black hat took the cautious perspective. The player in the yellow hat took the positive perspective. The player in the green hat took the creative-thinking perspective. The player in the blue hat took the directive control position. Kenny [14] tested this theory by designing six hat-related activities to instruct students in palliative care; the test had an excellent student response. Myers and Levin [15] used the six thinking hats to approach clinical problems. They found this approach provided a structure to examine a problem by efficiently exploring all aspects of an issue.

A computer game could use the "six thinking hats" strategy to explore all aspects of COPD care and to help the nursing student learn the essential components of COPD patient care in an active and interesting environment. The aims of this study were to develop a computer game of caring for patients with COPD in the outpatient clinic setting and to evaluate the nursing students' knowledge change and satisfaction score after they played this computer game.

\section{Method}

The research team took four months to discuss and develop the computer game for students caring for patients with COPD. The computer mouse, cursor, and keyboard were used to direct the game player to proceed or go back. The Fever Frenzy game dealing with hospital outpatient care of fever and disposition was selected as the game for the control group.

The COPD game environment was set at the outpatient clinic setting. The assessment and management of dyspnea, drug inhalation, keeping warm in cold weather, and breathing exercises were four units of COPD care. De Bono's six thinking hats [13], providing different perspectives on communication, were used to guide nursing students in their delivery of patient care. The six thinking hats were assigned to the nurse response, one for each of six clinics, so each of the six clinics represented one of the six possible perspectives proposed by de Bono.

There were scenario descriptions for each of the four symptom management unit. Participants took the nurse's role at each clinic, selecting the right answer from two response options. The wrong answers included incorrrect assessments, mismanagement of patients' symptoms, or examples of unprofessional communication.

The production of the virtual simulation system could be divided into three major parts: producing the virtual scenarios, developing the simulation system software program, and conducting the experiment and collecting the data. A personal computer was used to develop the teaching systems. The software tools used in this project included 3D Studio Max (3DS), Unity Game Engine, Photoshop, Visual Basic (VB), and Microsoft Access (Access). Table 1 shows the versions of the software tools used in this project. VB was used as the communication bridge between the operation of the game and completion of the pre- and post-tests. Through the VB programming code, this interface showed a pretest knowledge test, the experimental and control game, and, after 20 minutes of game playing, the post-test knowledge test. The satisfaction questionnaire was another post-test for the experimental group.

The COPD care knowledge test and satisfaction questionnaire were the evaluation instruments. Two faculty members were invited to review the 5 items of the COPD care knowledge test that was constructed by the research team for content validity. The COPD care knowledge test was modified according to these experts' comments.

The satisfaction questionnaire was developed by Tsai et al. [16]. It had 5 closed questions and three open questions. Content validity of this questionnaire was judged by five clinical nursing specialists with master's degrees.

\begin{tabular}{|c|c|}
\hline Functions & Software tools \\
\hline 1) Scenario production software & 3D Studio Max R5.1 \\
\hline 2) Virtual reality interactive simulation software & Unity 3.0 \\
\hline 3) Image processing software & Photoshop \\
\hline 4) Interface control programming software & Visual Basic 6.0 \\
\hline 5) Database software & Microsoft Access 2003 \\
\hline
\end{tabular}


Three junior nursing students from a university were invited to run the computer game to test the flow of the game after the University IRB approved this study proposal.

We invited 70 junior nursing students whose ages were around 20 to 22 years old to participate in this study. The research team assigned 35 participants to the control group and 35 participants to the experimental group with random assignments done in advance. The participants were scheduled to play the game at the university's computer laboratory during lunch break. Each participant used a personal computer and an earphone to listen the instruction and conversations in the game. The participants were asked not to speak to each other in the laboratory. Each participant finished the pretest, run 20 minutes game, and completed the posttest by following the designed program flow. The data were collected from April 15 to May 22, 2013.

\section{Results}

An introduction page showed a welcome greeting and guide to playing the COPD game. The game player went from the first to the sixth clinic for each of the four units. Each unit had one chief complaint. The patient's role was to express the same complaint in the six clinics and to receive the answer from the nurse for that clinic. Each clinic had a different nurse with a different response, so the patient would receive six different answers. The game-player's role was that of the clinic nurse. Whenever the game player finished one clinic, the color of the clinic would turn dark, and the colored hat wined by that clinic was showed on the screen.

For example, Figure 1 shows the first scenario designed by using the Unity Game Engine. It was a narrative of a 25-year-old nurse who was working at a pulmonary clinic in a teaching hospital. She had no history of smoking or any disease. A 75-year-old male COPD patient came to visit the clinic. The patient had a 40-year history of smoking and had quit smoking 5 years ago. He had already retired and was living with his family. He did not exercise regularly.

Figure 2 shows a nurse trying to assess the medical status of the patient. The patient stated that he had recently experienced frequent dyspnea.

The third scenario showed that the patient was taught to do breathing exercises, including pursed-lip breathing as shown in Figure 3.

In the COPD game, the student would receive several questions to answer (Figure 4). The student would need

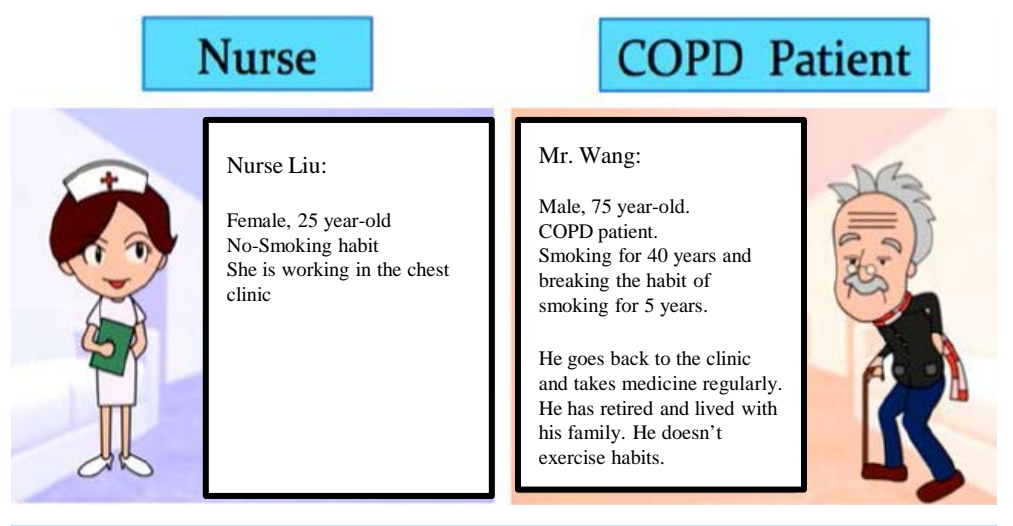

Figure 1. First scenario of visiting a pulmonary outpatient clinic.

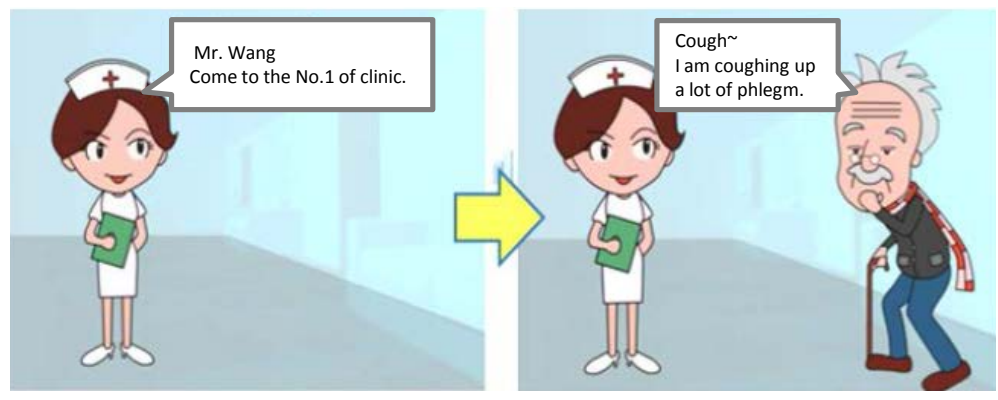

Figure 2. Patient's chief complain of cough. 


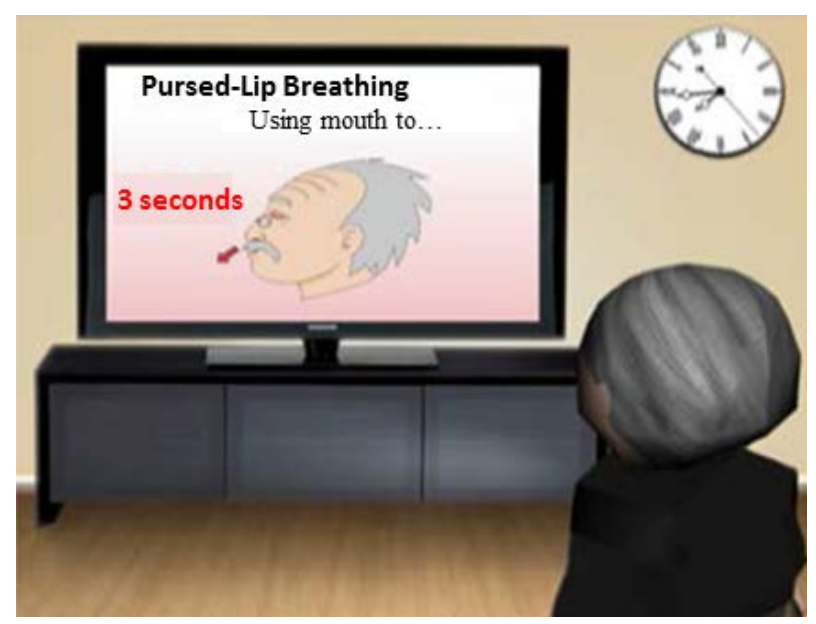

Figure 3. Breathing exercises of exhaling for three seconds.

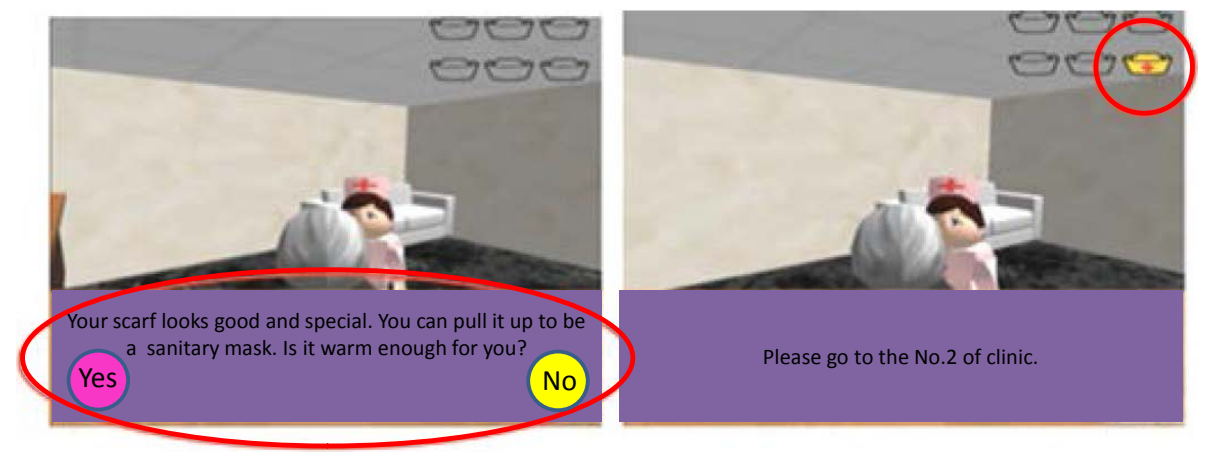

Figure 4. Conversation in the first clinic.

to choose Yes or No as the answer. If the student answered the questions correctly, the student would get credit for the particular color hat and could proceed to the next clinic.

The nurse said "The scarf color is beautiful, did the scarf keep you warm?" The player choosing yes for answer would get a yellow hat as indicated in the upper left corner.

After the participants finished the game and completed the posttest, the research team screened their answers carefully. Two participants in the experimental group gave conflicting answers in the satisfaction questionnaire. For example, one participant answered that she would continually engage in this kind of game-based learning to enhance her clinical ability, yet she chose "very dissatisfied" in the closed question. Thus, two data sets were deleted from the experimental group for data analysis. There were 35 data sets for the control group and 33 data sets for the experimental group.

The items included in the COPD knowledge test included management of weather change, dyspnea, drug inhalation and breathing exercises, all of which are important elements of COPD outpatient care. Difficulty and discrimination tests were conducted as part of the COPD knowledge test score. The range of discrimination index was 0.39 to 0.56 . The range of difficulty index was 50 to 81 . The discrimination and difficulty indexes were acceptable.

The mean pre- and post-COPD knowledge scores were 57.71 and 56, respectively, in the control group as shown in Table 2. There was no statistical difference. The mean pre- and post-COPD knowledge scores were 64.85 and 73.33 , respectively, in the experimental group. There was a significant difference as determined by the pair $\mathrm{t}$ test $(\mathrm{t}=2.24, \mathrm{p}=0.033)$.

For the satisfaction items, the highest score item was item 2, "Playing this computer game could reduce the anxiety of facing COPD patients by enhancing the learning process to ensure adequate knowledge" as shown in Table 3. The next highest score was item 3, "This game could help participants to establish confidence in providing outpatient care for patients with COPD". One participant responded as "very dissatisfied" in item 4, "the 
fluency of operating the game”. Most participants had positive responses to this game-based learning experience.

The daily computer use and computer game play experience were further analyzed. There were 18 participants who used a computer more than 3 hours each day and 15 participants who used a computer less than 3 hours each day. The satisfaction scores had no statistical difference between these two groups. Twenty participants played computer games more than 2 hours each day, and thirteen participants played computer games less than 2 hours each day. The satisfaction scores also had no statistical difference between those two groups.

Other comments on playing this game are described in Table 4. Most comments were positive and offered helpful suggestions. The negative comments received would be a good reference in modifying this game operation.

\section{Discussion}

Both the experimental and control groups played a computer game. The content of these two games were different. The experimental group played the COPD game. The COPD knowledge test results improved significantly after the participants played the COPD game. The control group, however, played a game not based on the elements of COPD care. The COPD knowledge test for the control group did not improve significantly. Hence, game-based instruction could be one strategy to help nursing students acquire knowledge of COPD care.

Table 2. COPD knowledge scores $(\mathrm{N}=68)$.

\begin{tabular}{cccc}
\hline Group & Pre/Post & Mean & Std. \\
\hline \multirow{2}{*}{ Experimental } & Pre-test & 64.85 & 20.02 \\
& Post-test & 73.33 & 16.33 \\
\multirow{2}{*}{ Control } & Pre-test & 57.71 & 23.65 \\
& Post-test & 56.00 & 18.66 \\
\hline
\end{tabular}

Table 3. Satisfaction questionnaire scores.

\begin{tabular}{cccccc}
\hline Questions & $\begin{array}{c}\text { Q1 } \\
\text { help caring } \\
\text { ability }\end{array}$ & $\begin{array}{c}\text { Q2 } \\
\text { reduce the } \\
\text { anxiety }\end{array}$ & $\begin{array}{c}\text { Q3 } \\
\text { establish } \\
\text { confidence }\end{array}$ & $\begin{array}{c}\text { Q4 } \\
\text { fluency of } \\
\text { operating }\end{array}$ & $\begin{array}{c}\text { Q5 } \\
\text { overall } \\
\text { safisfaction }\end{array}$ \\
\hline Very satisfied & $7(21.2 \%)$ & $11(33.3 \%)$ & $10(30.3 \%)$ & $7(21.2 \%)$ & $8(24.2 \%)$ \\
Satisfied & $17(51.5 \%)$ & $17(51.5 \%)$ & $15(45.5 \%)$ & $19(57.6 \%)$ & $18(54.5 \%)$ \\
OK & $9(27.3)$ & $4(12.1 \%)$ & $7(21.2 \%)$ & $6(18.2 \%)$ & $6(18.2 \%)$ \\
Dissatisfied & $0(0 \%)$ & $1(3 \%)$ & $1(3 \%)$ & $0(0 \%)$ & $1(3 \%)$ \\
Very dissatisfied & $0(0 \%)$ & $0(0 \%)$ & $0(0 \%)$ & $1(3 \%)$ & $0(0 \%)$ \\
\hline
\end{tabular}

Table 4. Comments on playing this game.

\begin{tabular}{c} 
Types \\
$\begin{array}{c}\text { This game helps us to understand more about the care of COPD patients. } \\
\text { The COPD breathing exercises on the video are very detailed and clear. } \\
\text { The situational animation about COPD makes a deeper impression on us. } \\
\text { This situational animation and video do not help } \\
\text { us choose the correct answer. } \\
\text { Puggestions } \\
\text { Perhaps this game could include more content about how } \\
\text { to deal with the acute symptoms of COPD. }\end{array}$ \\
\hline
\end{tabular}


Hartjes and Baumann [17] developed a web-based malaria-risk-reduction game and found the malaria knowledge test score improved after the students played the malaria-risk-reduction game. This study had findings similar to those of their study.

The pretest score for the experimental group was higher than control group. Two factors might contribute to this higher score. One was that the satisfaction question did not offer to the control group. Thus, there was no comparison between the answers of closed questions and open question. The number of knowledge score data in control group remained the same. But two sets of knowledge score data in experimental group was reduced because of the conflicting between the answers of closed questions and open question. The second factor might be due to the random error because they were randomly assigned to each group.

In the open question, one participant suggested adding content related to acute-symptom care. The acute-care contents were the major components of the medical-surgical nursing class. The outpatient care of COPD patients is important for long-term care. Yet, this content was seldom taught because it was only the second priority in the limited time frame of class teaching. It is suggested that the COPD game for outpatient care could be an accessorial content and teaching strategy. The use of this emerging technology is not seen as a replacement for traditional teaching approaches, but as complementing and enhancing the student experience [5].

One participant responded "very dissatisfied" in item 4, "the fluency of operating the game". One element of negative feedback was that "This situational animation and video do not help us choose the correct answer." These two results implied that the clarity of the guide for playing this game could be improved. There was room for improvement in the operation procedures.

The application of de Bono's theory in this study was intended to facilitate an interesting section on different methods of communication. Yet, the evaluation of this facilitation was limited. For the facilitating the learning experience, the reflection session might help to cognitively construct the six perspectives in responding to patients' symptoms. Cowley, Heikura, and Ravaja [18] conducted a serious game with reflection study design and found no difference between groups with or without reflection session. Yet, they argued that the learning between game play and reflection might interact recursively and unintended effect be raised. They still suggested reflection being learning strategy with serious game.

\section{Conclusion}

The knowledge score of the participant was significantly increased in the experimental group. This computer game could help nursing students gain knowledge related to taking care of patients with COPD. Most participants were satisfied with this computer game. Yet, it is not enough to have confidence in taking care of COPD patients. Also, the management of acute symptoms was not covered in this game. The fluency of operating this game still needs to be polished. The experience of developing this game could be the basis for developing the computer game for COPD patients.

\section{Acknowledgements}

The financial support from the National Science Council (NSC 101-2511-S-030-005) is greatly appreciated.

\section{References}

[1] Dayal, R., Faries, P.L., Lin, S.C., Bernheim, J., Hollenbeck, S., DeRubertis, B., Trocciola, S., Rhee, J., McKinsey, J., Morrissey, N.J. and Kent, K.C. (2004) Computer Simulation as a Component of Catheter-Based Training. Journal of Vascular Surgery, 40, 1112-1117. http://dx.doi.org/10.1016/j.jvs.2004.09.028

[2] Tsai, S.L., Tsai, W.W., Chai, S.K., Sung, W.H., Doong, J.L. and Fung, C.P. (2004) Evaluation of Computer-Assisted Multimedia Instruction in Intravenous Injection. International Journal of Nursing Studies, 41, 191-198. http://dx.doi.org/10.1016/S0020-7489(03)00130-5

[3] Heron, D.E., Andrade, R.S., Flickinger, J., Johnson, J., Agarwala, S.S., Wu, A., Kalnicki, S. and Avril, N. (2004) Hybrid PET-CT Simulation for Radiation Treatment Planning in Head-and-Neck Cancers: A Brief Technical Report. International Journal of Radiation Oncology, Biology, Physics, 60, 1419-1424. http://dx.doi.org/10.1016/j.ijrobp.2004.05.037

[4] Dye, J., Gillon, L. and Sales, R (2009) Benefits and Challenges of Interprofessional Collaboration in the Development of a Virtual Learning Environment. Journal of Interprofessional Care, 23, 95-97. http://dx.doi.org/10.1080/13561820802191242 
[5] Johnston, B., Boyle, L., MacArthur, E. and Manion, B.F. (2013) The Role of Technology and Digital Gaming in Nurse Education. Nursing Standards, 27, 35-38. http://dx.doi.org/10.7748/ns2013.03.27.28.35.s9612

[6] Chia, P. (2013) Using a Virtual Game to Enhance Simulation Based Learning in Nursing Education. Singapore Nursing Journal, 40, 21-26.

[7] Tinker, R. and While, A. (2006) Promoting Quality of Life for Patients with Moderate to Severe COPD. British Journal of Community Nursing, 11, 278-284. http://dx.doi.org/10.12968/bjcn.2006.11.7.21442

[8] Jonsdóttir, H. (2008) Nursing Care in the Chronic Phase of COPD: A Call for Innovative Disciplinary Research. Journal of Nursing and Healthcare of Chronic Illness, 17, 272-290. http://dx.doi.org/10.1111/j.1365-2702.2007.02271.x

[9] Lou, P., Chen, P., Zhang, P., Yu, J., Wang, Y., Chen, N., Zhang, L., Wu, H. and Zhao, J. (2015) A COPD Health Management Program in a Community-Based Primary Care Setting: A Randomized Controlled Trial. Respiratory Care, 60, 102-112. http://dx.doi.org/10.4187/respcare.03420

[10] Chen, K.-H., Chen, M.-L., Lee, S., Cho, H.-Y. and Weng, L.-C. (2008) Self-Management Behaviours for Patients with Chronic Obstructive Pulmonary Disease: A Qualitative Study. Journal of Advanced Nursing, 64, 595-604. http://dx.doi.org/10.1111/j.1365-2648.2008.04821.x

[11] Metcalf, B. and Yankou, D. (2003) Using Gaming to Help Nursing Students Understand Eethics. Journal of Nursing Education, 42, 212-215.

[12] Lever, K.A. (2005) Introducing Students to Research: The Road to Success. Journal of Nursing Education, 44, 470471.

[13] de Bono E. (1995) Edward de Bono’s Mind Pack. Dorling Kindersley, London.

[14] Kenny, L.J. (2003) Using Edward de Bono Six Hats Game to Aid Critical Thinking and Reflection in Palliative Care. International Journal of Palliative Nursing, 9, 105-112. http://dx.doi.org/10.12968/ijpn.2003.9.3.11484

[15] Myers, G. and Levin, R.F. (2009) Explore Clinical Problems by Wearing Different Hats. Research and Theory for Nursing Practice: An International Journal, 23, 5-7. http://dx.doi.org/10.1891/1541-6577.23.1.5

[16] Tsai, S.L., Chai, S.K., Hsief, L.F., Lin, S.L., Taur, F.M., Sung, W.S. and Doong, J.L. (2008) The Use of Virtual Reality Computer Simulation in Learning Port-A Cath Injection. Advances in Health Sciences Education, 13, 71-87. http://dx.doi.org/10.1007/s10459-006-9025-3

[17] Hartjes, L.B. and Baumann, L.C. (2012) Evaluation of a Web-Based Malaria Risk Reduction Game for Study Abroad Students. Journal of American College Health, 60, 403-414. http://dx.doi.org/10.1080/07448481.2012.667464

[18] Cowley, B., Heikura, T. and Ravaja, N. (2013) Learning Loops-Interactions between Guided Reflection and Experience-Based Learning in a Serious Game Activity. Journal of Computer Assisted Learning, 29, 348-370. http://dx.doi.org/10.1111/jcal.12013 